\title{
CONVENIENCE AND CIRCUITY IN A SHORT-HAUL MODEL OF AIR PASSENGER DEMAND
}

\author{
Manuel G. Russon and Craig A. Hollingshead*
}

\section{Introduction}

Aviation practitioners and interested academicians are concerned with identifying the determinants of airline passenger demand. In general, variables affecting air passenger demand can be classified into three categories; gravitational (e.g. population and distance), activity (e.g. per capita income or employment composition), and quality of service variables (e.g. convenience, fare, flight frequency, and seat availability). Douglas and Miller (1974) and Anderson and Kraus (1981) use multiple regression analysis to support the hypothesis that the number of enplaned passengers (demand) is sensitive to these variables.

One problem with estimating a model of air passenger demand in the short-haul market is determining the sensitivity of enplaned passengers to the distance between city-pairs. In extremely short-haul markets, while demand for all modes of travel between city-pairs is high, air passenger demand will be low due to the greater convenience of automobile transport. As distance increases there are two off-setting effects. First, the differential convenience of air over automobile travel is increased, therefore, the number of enplaned passengers should increase. On the other hand, the distance decay (gravitational attraction) model predicts that as distance increases, economic interaction will decrease, therefore, air passenger demand will decrease. Figure 1 illustrates the combined effects of convenience and distance decay. Below threshold distance $x$, there will be no market for air transport since the convenience of air travel does not exceed that of automobile travel. As distance increases beyond $x$, the convenience associated with air transport dominates the effect of distance decay and enplaned passengers will increase. Beyond some point, $\mathrm{D}^{*}$, the distance decay effect will dominate convenience and the number of enplaned passengers will decrease.

Studies of air passenger demand have not separated the direct relationship between enplaned passengers and convenience from the inverse relationship between enplaned passengers and distance decay. For example, Ippo-

\footnotetext{
-Assistant Professor of Management, and Assistant Professor of Marketing and Transportation, University of South Alabama, Mobile, AL, respectively.
}

lito (1981) used distance as a proxy for convenience of air transport over automobile and he found a positive and significant relationship between distance and demand. Whitehurst and McKnew (1982) quantified convenience directly using flight time and driving time as explanatory variables. Only the flight time had a positive and significant coefficient, indicating increased convenience of flying over driving as distance increases. Their study did not address the effect of distance decay explicitly.

The objective of this research is to advance a more precise measure of convenience in the short haul market for air transportation. In addition to flight frequency, convenience is hypothesized to be a function of travel time, degree of circuity of connecting flights, and possible competition from alternative modes of travel. This more precise measure of convenience permits separation of the effect of convenience from the distance decay effect on enplaned passengers where no such separation was made previously. The results support the conclusions of previous research, that in the short-haul market enplaned passengers are an increasing function of population densities, flight frequency, and income. Furthermore, the results indicate that enplaned passengers are an increasing function of convenience, a decreasing function of circuity, and a decreasing function of the availability of more rapid alternative modes of travel. The simultaneous measurement of quality of service and distance decay permits determination of the approximate distance, $\mathrm{D}^{*}$ at which convenience gives way to the distance decay effect.

\section{A Short Haul Model for Air Passenger Demand}

Simple demand models of air transportation include population, distance, income, and fare. More intricate models incorporate mode of choice and delay factors. In this model of air passenger transport, origin-destination demand is generated by population in each city-pair, per capita income in each city, distance between city-pairs, and quality of service variables, measured by flight frequency and travel time differential between air and automobile.

Business and social interaction is the basis of demand for all air passenger travel. Origin population constitutes the pool of potential passengers, and destination population measures attraction. Thus enplaned air passen- 


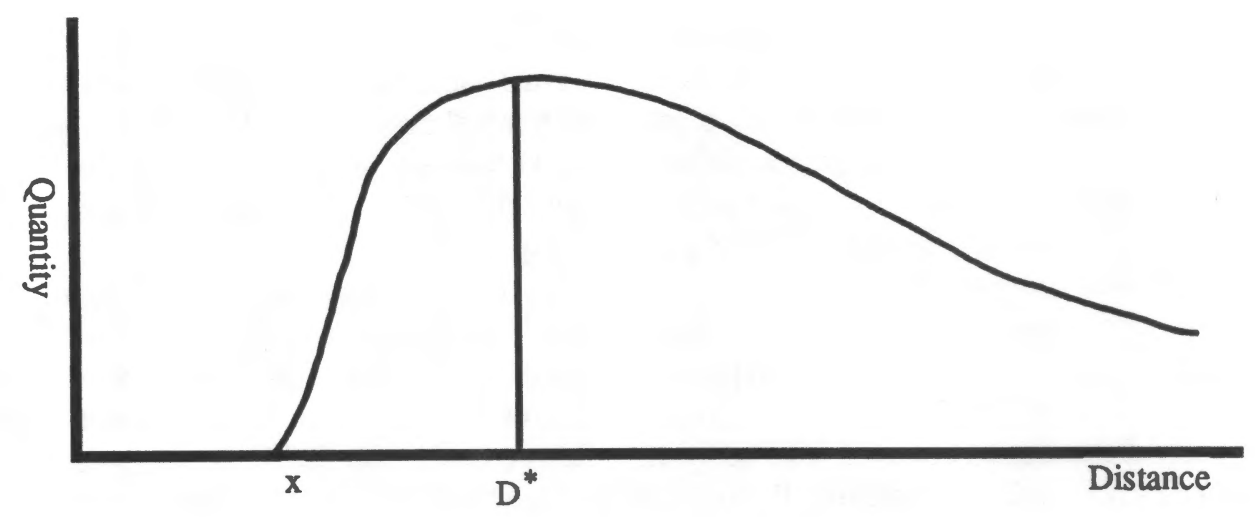

Figure 1. Air Passenger Demand

gers should increase with greater population at either origin or destination.

Gronau (1970) holds modal choice to be an economic decision; people seek to minimize their total cost of travel. Total travel cost is the out-of-pocket cost of transport plus the value travelers place on personal travel time. Personal travel time is the interval between departure from home or office until arrival at the final destination. In the case of air transport this includes local transit time, origin terminal processing, waiting time until the next flight, time in the air, waiting at intermediate stops, baggage claim, and destination local transport.

An increase in frequency of service reduces the waiting time until the next flight and, therefore, decreases the waiting cost component of total travel cost. As total cost of air transport declines relative to the cost of a competing mode there should be an increase in enplaned passengers: This increase in enplaned passengers should occur at a decreasing rate until the marginal productivity of an additional flight becomes zero at some saturation point.
From a gravitational perspective, per capita income is a measure of the magnitude of macroeconomic mass or potential for interaction between populations. From a microeconomic perspective, per capita income quantifies the value of personal time for the social traveler and the opportunity cost of time to a firm for the business traveler. As income increases, time becomes more valuable and air travel becomes relatively more attractive for both business and social travelers. Thus, air travel will be substituted for automobile travel ${ }^{1}$.

The transit time component of total travel cost is minimized in the instance of non-stop air travel but increases with the number and duration of intermediate stops, and the circuity of the route. For example in Figure 2 , above, transit time is minimized with non-stop service, is greater through intermediate stop $A$, and greatest through intermediate stop $B$, the route with the greatest circuity. As the transit component of total travel time increases, the cost of air transport increases relative to automobile transport and the number of enplaned passen-

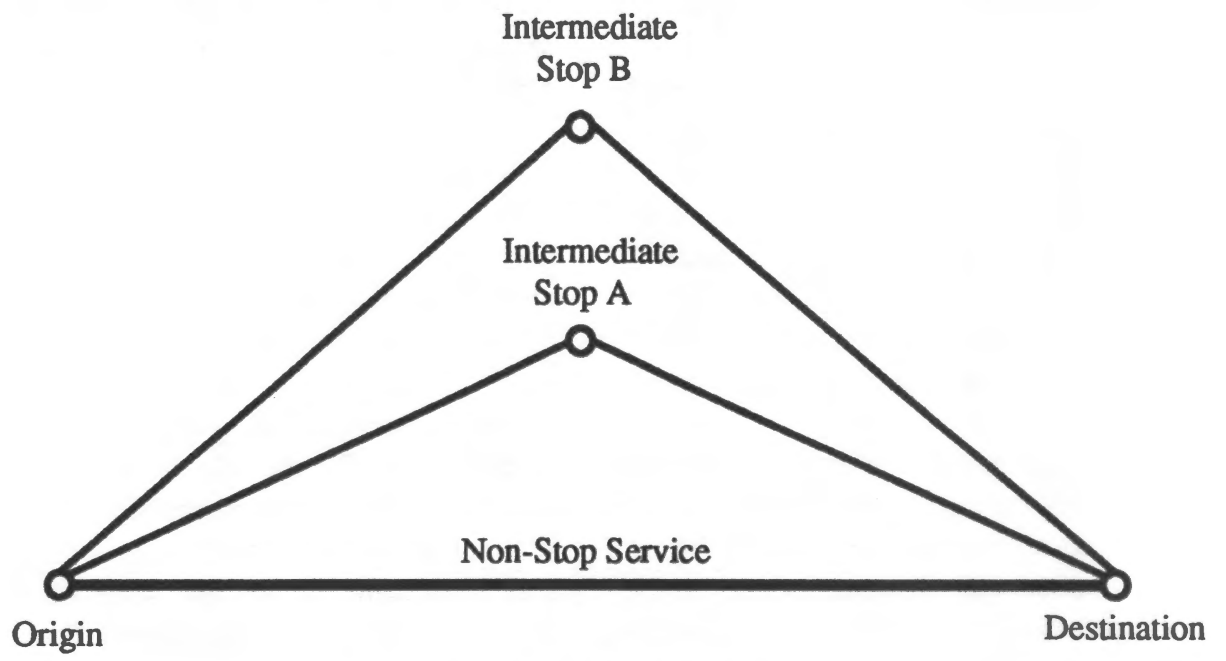

Figure 2. Airline Routing Circuity 
gers should decrease. When the transit time component of air travel increases to make the total travel cost of flying greater than that of driving, the number of enplaned passengers should fall to zero irrespective of population, income, or flight frequency. Therefore, enplaned passengers should be an increasing function of the difference between driving time and flying time.

Non-stop and connecting flight frequencies should have different impacts on the number of enplaned passengers as a consequence of different travel times (hence different travel costs). ${ }^{2}$ Separating non-stop from connecting flight frequencies and adding the driving/flying time differential enables this model to describe more fully the effect of the convenience variable on the decision to drive or fly.

As indicated in the introduction, the enplaned passengers function of distance is a complex interaction of convenience and distance the decay effect. Distance decay is a phenomenon that describes the decreased interaction between masses with increased distance. In the case of air transport it refers to the passenger flow decline between city-pairs with increased distance. Moryadas and Lowe (1975) describe how the friction imposed by increased distance causes business and social interaction to decline. Over short distances enplaned passengers increase with increased distance as the convenience of air transport dominates distance decay. At some distance the distance decay effect dominates convenience, and the number of enplaned passengers decreases.

The model of air passenger demand to be estimated is:

$$
\begin{aligned}
& ++\quad-\quad++ \\
& Q=f\left(Y, P, M-x,[M-x]^{b}, N, C, D C\right) \\
& \mathrm{Q} \quad=\text { Total number of city-pair air passengers per } \\
& \mathrm{P}=\text { Productof respective city-pair populations }{ }^{4} \\
& \mathrm{Y}=\text { Geometric mean of respective per capita in } \\
& \text { come in the cities-pairs }{ }^{5} \\
& \mathrm{M}-\mathrm{x}=\text { Distance, highway miles between city-pairs, } \\
& \mathrm{M} \text {, minus } \mathrm{x} \text {, the threshold flying distance }{ }^{6} \\
& \mathrm{~N}=\text { Number of non-stop flights per week }{ }^{7} \\
& \mathrm{C}=\text { Number of connecting flights per week }{ }^{8} \\
& \mathrm{DC}=\text { Driving time minus connecting flight time }{ }^{9}
\end{aligned}
$$

The signs above the variables indicate the expected signs of the partial derivatives on enplaned passengers. The threshold distance, $x$, corresponds to the point in Figure 1 where the function intersects the distance axis.

There is no need to adjust the linear and quadratic non-stop terms to reflect the non-stop flying time differen- tial. The simple correlation coefficient of 0.994 indicates a virtual linear transformation between distance and the nonstop travel time differential. However, the correlation of 0.941 between distance and connecting time differentials is weaker owing to the varying degree of circuity between city-pairs of given distances.

Conspicuously absent from the model is a proxy for fare. ${ }^{10}$ Following Brueckner (1985) price is assumed to be an endogenous function of the other independent variables. Therefore, estimation of this model assumes a reduced form equation implicitly includes the effect of price on enplaned passengers. Also absent are prices of competing modes of travel. The out-of-pocket costs of operating an automobile are assumed to be equal throughout the region considered. Travel by train is not an option in the South due to lack of route coverage and infrequency of schedules. Bus travel also is not an option due to the excessive inconvenience of logistics and travel time. There also may be such a clientele effect associated with bus travel that the majority of air passengers do not consider it an acceptable alternative.

\section{Method and Analytical Technique}

Multiple regression analysis is used to explain variation in the number of origin-destination passengers for a cross- section of 458 city-pairs selected from 35 Southeastern cities ${ }^{11}$. This constitutes a short-haul market as the maximum city-pair distance is 650 miles. Some city-pairs had only non-stop service, some had only connecting service, some had both. The number of enplaned passengers during the 12-month period ranged from zero to 98,000 . Observations with zero enplaned passengers and non-zero flight frequencies were included since a correct model of air transport will explain low volume routes as well as high volume routes. Observations with zero nonstop and connecting frequencies, and therefore zero enplaned passengers, were excluded in order not to bias explanatory power.

Conventional models of air passenger demand specify all variables in natural or common logarithms to account for interdependences between independent variables. In this study, however, specification of the variables in logarithmic form would be inappropriate for two reasons. First, many of the 458 observations had zero enplaned passengers. Many city-pairs also had zero non-stop or connecting flights. Use of the natural logarithm would result in numerous missing values since the natural logarithm of zero is undefined. Second, the number of non-stop and connecting flights has independent effects on the number of enplaned passengers. The antilog of a model specified with logarithmic terms would be inaccurate since 
a zero value for $\mathrm{N}$ or $\mathrm{C}$ would render the entire term equal to zero. Using interaction terms to account for interdependences between variables permits observations with zero enplaned passengers and/or zero non-stop or connecting flights to be included in the data set. This also separates the independent influence of $\mathrm{N}$ and $\mathrm{C}$ on enplaned passengers.

Combining the variables into interaction terms, the specification is:

$$
\begin{aligned}
& \mathrm{Q}=\mathrm{f}\left(\mathrm{YP}^{\mathrm{a}} \mathrm{N}^{\mathrm{c}}[\mathrm{M}-\mathrm{x}], \stackrel{-}{\mathrm{YP}^{\mathrm{a}} \mathrm{N}^{\mathrm{c}}[\mathrm{M}-\mathrm{x}]^{\mathrm{b}},}\right. \\
& + \\
& \left.Y^{2} C^{d}[M-x] D C, Y^{a} C^{d}[M-x]^{b} D C\right)
\end{aligned}
$$

All independent variables were assumed to be exogenous. The exponents of $\mathrm{N}$ and $\mathrm{C}$ were set equal to 0.7 , a value consistent with diminishing returns to flight frequency. ${ }^{12}$ Thus as $\mathrm{N}$ or $\mathrm{C}$ increases, the number of enplaned passengers will increase, but at a decreasing rate. If $\mathrm{N}$ and $\mathrm{C}$ are equal to zero, then assuming an intercept value of zero, enplaned passengers will be zero. The exponent for income is assumed to be $1.0^{13}$. Therefore, increases in income will have a linear effect on $\mathrm{Q}$.

Assuming that the number of enplaned passengers increases with population at an increasing rate, the exponent that attaches to population, a, was set equal to 1.1. This corrected an extreme and consistent pattern of error terms in the residuals that indicated a non-linear relationship between population and enplaned passengers.

If the value of $b$ were equal to 2.0 , estimation of the function would yield coefficients that conform to an inverted parabola as a function of distance. This would have the effect of generating a maximum number of enplaned passengers for some distance, and also a negative estimate for $\mathrm{Q}$ for some longer distance. In actuality the function should begin to decrease beyond some maximum point and asymptotically approach the horizontal (distance) axis, Figure 1. Any value for the exponent of the quadratic distance term greater than 1.0 and less than 2.0 will have the effect of skewing the parabolic function to the right, and increasing the distance at which the function crosses the horizontal axis. This exponent value was set equal to $1.5^{14}$.

It was assumed that no one would fly in the case where $M$ is less than 60 miles or where flying time exceeds driving time, i.e., $\mathrm{DC}<0 .{ }^{15}$ Hence, observations with $\mathrm{DC}$ less than zero arbitrarily were set equal to zero making the value of the whole expression zero, i.e., the parabola in Figure 1 is flat and $\mathrm{Q}$ becomes zero for all distances for which driving is faster than flying. This results in a truncated functional form for DC for observations where driving time is less than flying time. Including the time associated with circuity as an adjunct to the connecting flight frequencies adds information regarding the delay associated with connecting flights and should permit a more accurate estimate of the sensitivity of $Q$ to the number of non-stop and connecting flights.

\section{Results}

The first equation estimated was an elementary interaction model that included income, population, and frequency of service as explanatory variables but excluded the effects of convenience and distance decay. The results of this model were used as a bench-mark against which other models were evaluated. The functional form of the model was:

$$
\mathrm{Q}=\begin{array}{r}
++++ \\
\mathrm{f}(\mathrm{Y}, \mathrm{P}, \mathrm{N}, \mathrm{C}
\end{array}
$$

and it was specified as:

$$
\mathrm{Q}=\mathrm{f}\left(\stackrel{+}{\mathrm{YP}^{1.1}} \mathrm{~N}^{\cdot 7}, \stackrel{+}{\left.\mathrm{YP}^{1.1} \mathrm{C} \cdot \mathrm{7}\right)}\right.
$$

The regression results of the first specification were:

$\begin{array}{llll}\text { Variable } & \text { Estimate } & \text { T value } & \mathrm{r}^{2} 0.7732 \\ \text { Intercept } & 6.512 & 1.852 & \mathrm{r}^{2} \text { adj } 0.7722 \\ \text { YP }^{1.1} \mathrm{~N}^{\cdot 7} & 1.216 \mathrm{e}-10 & 38.908^{\circ *} & \text { F value } 775.604^{-* *} \\ \text { YP. }^{1.1} \mathrm{C}^{.7} & 2.655 \mathrm{e}-11 & 2.746^{\circ *} & \end{array}$

- Significant at $1 \%$

Following Ippolito (1981) the second model introduced distance between city-pairs as a proxy for the convenience of air travel relative to automobile travel. The functional form of this model was:

$$
\begin{gathered}
+\stackrel{+}{+}+\stackrel{+}{+} \\
\mathrm{Q}=\mathrm{f}(\mathrm{Y}, \mathrm{P}, \mathrm{N}, \mathrm{C},[\mathrm{M}-60])
\end{gathered}
$$

and it was specified as:

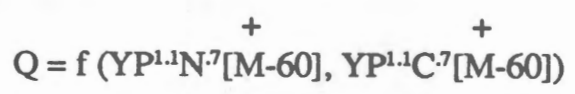

The anticipated positive sign above each variable indicates that as distance increased above 60 miles, air travel became relatively more attractive and the number of enplaned passengers increased. 
The regression results of the second model were:

\begin{tabular}{|c|c|c|c|}
\hline Variable & Estimate & $\mathrm{T}$ value & $r^{2} 0.9544$ \\
\hline Intercept & 2.323 & 1.468 & $r^{2}$ adj 0.9542 \\
\hline $\mathrm{YP}^{1.1} \mathrm{~N}^{\cdot ?}[\mathrm{M}-60]$ & $9.917 e-13$ & $96.617^{*}$ & F value $4756.413^{*}$ \\
\hline $\mathrm{YP}^{1.1} \mathrm{C}^{\cdot 7}[\mathrm{M}-60]$ & $1.038 e-13$ & $5.503^{*}$ & \\
\hline
\end{tabular}

'Significant at $1 \%$

The explanatory power of the model was high with just over 95 percent of the variation in enplaned passengers being explained by variation in the independent variables. ${ }^{16}$ The equation was statistically significant and the coefficients for all terms are significant and had the anticipated signs. The intercept was not statistically different from zero. By construction, the number of enplaned passengers increased with income and population in a linear fashion, and with flight frequency at a decreasing rate. Consistent with a priori expectations, the number of enplaned passengers was an increasing function of distance.

In the third model an exponential distance term was introduced to test for the distance decay effect. The model became:

$$
\begin{gathered}
+\stackrel{+}{+}+\stackrel{+}{+}+\stackrel{-}{\mathrm{Q}}=\mathrm{f}\left(\mathrm{Y}, \mathrm{P}, \mathrm{N}, \mathrm{C},[\mathrm{M}-60],[\mathrm{M}-60]^{1.5}\right)
\end{gathered}
$$

The anticipated negative coefficient on the exponential mileage term reflects the hypothesis that the number of enplaned passengers began to decrease at the point where the distance decay effect dominated convenience.

The new specification is:

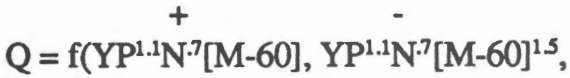

$$
\begin{aligned}
& + \\
& \left.Y P^{1.1} C^{\cdot 7}[M-60], Y P^{1.1} C^{7}[M-60]^{1.5}\right)
\end{aligned}
$$

The regression results of this specification were:

\begin{tabular}{llr} 
Variable & Estimate & T value \\
\hline Intercept & 2.113 & $1.692^{* *}$ \\
YP $^{1.1} \mathrm{~N}^{\cdot 7}[\mathrm{M}-60]$ & $1.785 \mathrm{e}-12$ & $34.641^{*}$ \\
$\mathrm{YP}^{1.1} \mathrm{~N}^{\cdot 7}[\mathrm{M}-60]^{1.5}$ & $-1.597 \mathrm{e}-13$ & $-15.474^{*}$ \\
$\mathrm{YP}^{1.1} \mathrm{C}^{\cdot 7}[\mathrm{M}-60]$ & $-8.062 \mathrm{e}-13$ & $-6.240^{*}$ \\
$\mathrm{YP}^{1.1} \mathrm{C}^{\cdot 7}[\mathrm{M}-60]^{1.5}$ & $1.667 \mathrm{e}-13$ & $7.087^{*}$
\end{tabular}

$r^{2} 0.9717$

$r^{2}$ adj 0.9715

F value $3888.621^{\circ}$

-Significant at $1 \%$

- Significant at $5 \%$
Two of the terms had unanticipated signs that affected inferences regarding distance decay and convenience but the model was correct on the effects of income, population and flight frequency. The F-test for the inclusion of additional explanatory variables supported rejection of the null hypothesis and the conclusion that the expanded model explained a significantly greater portion of the variation in passenger numbers than the preceding model ${ }^{17}$.

Finally the model was refined to include the effect of circuity and the delay associated with connecting flights. The model took the form:

$$
Q=f\left(Y, P, N, C, D C,[M-60],[M-60]^{15}\right)
$$

The final specification in interaction form was:

$$
\begin{aligned}
& \mathrm{Q}=\mathrm{f}\left(\mathrm{YP}^{1.1 \mathrm{~N}^{\cdot ?}} \stackrel{+}{+} \stackrel{-}{-}\right. \\
& + \\
& \left.\mathrm{YP}^{1.1} \mathrm{C}^{\cdot ?}[\mathrm{M}-60] \mathrm{DC}, \mathrm{YP}^{1.1} \mathrm{C}^{.7}[\mathrm{M}-60]^{1.5} \mathrm{DC}\right)
\end{aligned}
$$

\begin{tabular}{|c|c|c|c|}
\hline Variable & Estimate & T value & $r^{2} 0.9723$ \\
\hline Intercept & 1.358 & 1.117 & $r^{2} \operatorname{adj} 0.9721$ \\
\hline $\mathrm{YP}^{1 \cdot 1} \mathrm{~N}^{-1}[\mathrm{M}-60]$ & $1.778 e-12$ & $34.977^{\circ}$ & F value $3976.561^{\circ}$ \\
\hline $\mathrm{YP}^{1.1} \mathrm{~N}^{\cdot 7}[\mathrm{M}-60]^{1.5}$ & $-1.591 e-13$ & $-15.598^{*}$ & \\
\hline $\mathrm{YP}^{\mathrm{L}} \mathrm{C}^{\cdot 7}[\mathrm{M}-60] \mathrm{DC}$ & $5.242 e-13$ & $5.514^{*}$ & \\
\hline $\mathrm{YP}^{1.1} \mathrm{C}^{-7}[\mathrm{M}-60]^{1.5} \mathrm{DC}$ & $-7.941 \mathrm{e}-14$ & $-4.999^{\circ}$ & \\
\hline
\end{tabular}

Increases in circuity were anticipated to have a positive effect on the number of enplaned passengers. Therefore, each connecting term retained sign anticipated in the third model.

The regression results of the fourth model were:

Regression results were as expected with all variables displaying the a priori expected signs. Inclusion of the circuity variable increased the explanatory power of the model to 0.9723 . The F-Statistic was significant at the 1 percent level. ${ }^{18}$ The coefficients of the linear and exponential mileage terms were positive and negative, respectively, and both were statistically significant.

The feature that distinguished this model from the third one was inclusion of a travel time differential between driving and flying on connecting flights. Increases in circuity and the delay associated with connecting service 
decrease DC and hence the number of enplaned passengers. The significance of this result is related to the notion that an increased number of passengers could be obtained by diminishing the circuity and/or delay for a given distance. This could be accomplished by using faster equipment, reducing connecting times, or by reducing circuity via more strategically placed hubs. The reduced air transit time associated with any of these would have the effect of increasing the travel time differential in favor of air transport.

These results also demonstrate that the number of enplaned passengers was an inverted and skewed parabolic function of distance that corresponded to the function in Figure 1. Thus the number of enplaned passengers increased with distance in ranges in which convenience dominated the distance decay effect. At greater distances the number of passengerd decreases as distance decay dominated convenience.

The model is correct theoretically in that the intercept term is not significantly different from zero. Furthermore, assuming the intercept is zero, if the number of nonstop and connecting flights were zero, the number of enplaned passengers would be zero irrespective of population, distance, or driving time. As the number of non-stop or connecting flights increases, the number of enplaned passengers increases at a decreasing rate. Further, the gain in enplaned passengers with increased flight frequency depends on population densities and income at origin and destination. As the income or population of either origin or destination increases the number of enplaned passengers increases.

Sensitivity analysis was performed on the values of the exponents of the variables that comprise the interaction terms. The explanatory power and significance of the coefficients were not sensitive to variation in these exponents.

\section{Conclusions}

This research supports the conclusions of studies that hold the number of enplaned passengers to be an increasing function of population densities, income, and non-stop and connecting flight frequencies. The contribution of this study is to measure more accurately the convenience variable in-so-far as it affects the decision to drive or fly. This study demonstrates that convenience should be measured in terms of flight frequency and travel time differential. This more accurate measure of convenience makes it possible to separate convenience from the distance decay effect, and to measure the effect of distance decay on enplaned passengers in a short-haul market. To the extent that this model explains and/or predicts more accurately the number of origin-destination passengers for specific city-pairs, the model should be useful to airline managers as a planning tool with which to identify potentially profitable markets. The model also should be of benefit to city planners interested in attracting or increasing air service.

This research also demonstrates that short-haul air travel can be generated to the extent that the convenience of air transport - measured in terms of flight frequency and travel time differential - exceeds that of competing modes of travel. The decision to drive or fly is an economic one in which the total travel cost is minimized. Since the total cost of air transport is the sum of out-of pocket costs plus the value of total travel time, reducing transit time reduces total cost and increases the propensity to fly. This increases the number of enplāned passengers as travelers substitute air transport for travel by auto.

This analysis provides support for the hypothesis that regional air transport could be enhanced through use of multiple municipal airports. The distance and the urban congestion involved in commuting to an airport increase the travel time and total cost of air transport. Multiple municipal airports could decrease local transit time at the origin or destination to induce short-haul air travel that otherwise would not be economically advantageous. This is especially true for extremely short-haul markets in which local commuting is a significant percentage of total travel time.

Finally, this study demonstrates that regional air transport can be enhanced through the strategic placement of hubs. Where regional air transport is excessively circuitous due to the location of a particular hub, a more strategically located hub could reduce the circuity component of travel time enough to induce substitution of air transport for automobile travel, or to divert traffic from an inconveniently located hub.

\section{Notes}

'The magnitude of this effect should be less for the business traveler than for the social traveler as the elasticity of enplaned business passengers with respect to income is not as high. Due to data limitations, business and social travel are aggregated and passengers are treated as homogeneous with regard to purpose of travel.

${ }^{2}$ The impact also may be different due to the degree to which travelers wish to avoid intermediate stops.

${ }^{3}$ Data were obtained from Origin-Destination Survey, 10 percent Sample, Air Transport Association, for the period March1, 1984 - April 31, 1985. Data from the 10 percent sample were multiplied by 10 to give an unbiased estimate of enplaned passengers for the 12 month period and divided by 52 
to obtain weekly estimates.

4Population is the population of the CMA, or where a city is not in a CMA, the population of the county or counties in which the city is located. Data were obtained from the 1980 census.

SPer capita income data were obtained from Statistical Abstract. 1984.

${ }^{6}$ Distance is highway mileage obtained from Rand McNally Highway Atlas.

${ }^{7}$ Flight frequency data were obtained from the Official Airline Guide (December 15, 1984). It is assumed that information in this issue of the OAG is representative of the entire 12 month period under study.

${ }^{8} \mathrm{Ibid}$. In cases where the OAG did not list connecting flights, connecting schedules for those city-pairs were constructed from flight availability to known connecting hub (or hubs). Direct service, i.e. situations in which scheduled service includes stops enroute with no change of plane, is treated as a connecting flight in this study.

${ }^{9}$ Driving time was computed by dividing the road mileage between city pairs by $50 \mathrm{mph}$ - and adding 15 minutes local transit time on each end of the journey. Non-stop and connecting air travel time was determined directly from the OAG. In cases where connecting flight schedules were not shown, flying times for the component route segments were combined and a delay of 60 minutes was added for each intermediate stop. A standard 45 minutes was added to all non-stop and connecting travel times to account for local transit time, ticketing, baggage claim, and related activities.

${ }^{10}$ During the time period from which the data were drawn numerous fares were available for each city-pair, depending on class of travel, time of travel, advance purchase restrictions, etc. The airlines considered specific numbers of passengers and the associated fares proprietary information would not make available.

${ }^{11}$ East Georgia to West Mississippi, the Gulf Coast to Nashville. Populations ranged from Natchez, MS $(50,000)$ to Atlanta $(2,000,000)$.

${ }^{12}$ The assumption of 0.7 follows the results given by Ippolito (1981). His estimated elasticity for flight frequency was 0.755 .

${ }^{13}$ In the absence of an intuitive justification for selection of an alternative parameter, income elasticity was assumed to be 1.0.

${ }^{14}$ Due to the short-haul focus of the analysis, we assumed that the distance at which $\mathrm{Q}$ approaches and becomes zero is outside the range of relevant distances.

${ }^{15}$ The threshold distance certainly was greater than 40 miles and less than 150 miles. While 60 miles appears to an arbitrary estimate, it was an improvement over not adjusting the term at all.

${ }^{16}$ No statistical test was needed to test for increased explanatory power since the number of degrees of freedom was the same.

${ }^{17}$ The F-test is given by:

$$
\begin{gathered}
\mathrm{F}=\frac{\text { SSRq }- \text { SSRk }}{\text { SSEq }} \times \frac{\mathrm{n}-\mathrm{Q}}{\mathrm{Q}-\mathrm{K}} \\
\mathrm{F}=\frac{9647578.95-9475342.43}{453207.14} \times \frac{458-4}{4-2}=86.27
\end{gathered}
$$

For the mathematics and a discussion of this test see Kmenta (1986).

${ }^{18}$ No statistical test was needed to test for increased explanatory power since the number of degrees of freedom is the same.

\section{References}

Anderson, James E. and Marvin Kraus, "Quality of Service and the Demand for Air Travel," The Review of Economics and Statistics, November 1981, pp. 533-540.

Brueckner, Jan K., "A Note on the Determinants of Metropolitan Airline Traffic," Rivista Intemazionale di Economia dei Transporti (Rome), V12N2, June 1985, pp. 175-84.

Douglas, George W. and James C. Miller, III, Economic Regulation of Domestic Air Transport, Washington, D.C.: The Brookins Institution, 1974, pp. 39-60.

Gronau, Reuben, The Value of Time in Passenger Transportation: The Demand for Air Travel, Occasional Paper 109, National Bureau of Economic Research: New York, 1970.

Ippolito, Richard A., "Estimating Airline Demand with Quality of Service Variables," Journal of Transport Economics and Policy, January 1981, pp. 7-15.

Kmenta, Jan, Elements of Econometrics,Second edition. New York, NY: Macmillian Publishing Company, 1986, pp. 416422.

Moryadas, S. and John C. Lowe, The Geography of Movement, Boston, MA: Houghton Mifflin Company, 1975, pp. 176208.

Whitehurst, Clinton H., Jr., and Mark A. McKnew, "Identifying Potentially Profitable Commuter Airline Routes in South Carolina: A Report," Business and Economic Review, V28N5, April 1982, pp. 42-46. 